\title{
Determining the Directions of Specialist Preparation Development in the Specialty 026 Performing Arts Based on the Survey Results of Applicants for Higher Education
}

\author{
Roman Nabokov $^{1, *}$, Sergii Gordeev ${ }^{1}$, Mykola Krypchuk $^{2}$ and Viktoriia Buhaiova ${ }^{1}$ \\ ${ }^{1}$ Kharkiv State Academy of Culture, Bursatsky Uzviz, 4, Kharkiv, 61057, Ukraine \\ ${ }^{2}$ Kyiv National University of Culture and Arts, 36 Yevhen Konovalets str, Kyiv, 01601, Ukraine \\ *Corresponding author. Email: nabokofff@gmail.com
}

\begin{abstract}
The material considers the problem of the lack of the standard of Ukraine's higher education of the first (bachelor) level of specialty 026 Performing arts (field of knowledge 02 Culture and art).

According to the survey results of stakeholders (applicants for higher education) of Ukraine's several higher education institutions, the elements of the draft of such a standard and ways of development of higher education institutions that provide such training are proposed. Applicants should be trained only in a dual education system, which involves on-the-job training in enterprises, institutions, and organizations to acquire a certain qualification. Proposals formed by applicants are those new pedagogical conditions that need to be organized and implemented in the educational process: to form a system of information support of the educational process and feedback with applicants; to form a professional development system of scientific and pedagogical workers of higher education institutions.
\end{abstract}

Keywords: standard of Ukraine's higher education, specialty 026 Performing arts, survey, stakeholders, applicants for higher education, training development

\section{INTRODUCTION}

Although the new list of areas of knowledge and specialties in which the training of applicants for higher education is carried out, approved in 2015 [1], the standard of Ukraine's higher education of the first (bachelor's) level in specialty 026 Performing arts (field of knowledge 02 Culture and art) has not yet been developed [2] and approved [3]. According to Art. 10. of the Law of Ukraine On Higher Education "The standard of higher education is a set of requirements for educational programs of higher education, which are common to all educational programs within a certain level of higher education and specialty" [4]. The lack of higher education standards leads to the fact that each institution of higher education carries out training within the same specialty at its own discretion and the content of education programs differs significantly, there is almost nothing in common. This situation has a negative impact on the quality of higher education training. The lack of quality education of higher education seekers and the availability of education services of foreign higher education institutions lead to educational migration, which is revealed in the publications of scientists M. Medvid, O. Komisarov, O. Merdova [5]. According to the study, they "made a conclusion that there is no suitability among a real life and equal social-economic conditions of forming by able-bodied people all necessary competencies and their improvement and also the using of acquired human capabilities by process of creation of welfare, which threats sustainable development". The standards of higher education define the requirements for the educational program, and the most important requirement is a list of mandatory competencies of the graduate [4].

\section{PROBLEMS AND METHODOLOGY}

Conditions for teaching specialists in Performing Arts have been the subject of research by many scientists, including N. Gusakov [6]. The most important stakeholder is applicants for higher education. After participating in practical activities in the performing arts, they can assess what competencies they should form and what conditions for their formation should be created in higher education institutions.

Almost all US and European higher education institutions have strategic planning and institutional research units. Their task is to conduct a survey of applicants, determine the level of their satisfaction with learning, find out what needs to be noticed in the preparation process. Making changes in the content of the educational preparation and in the process of educational activities of higher education institutions is carried out to take into account the opinions of students so that they remain to study in the institution, 
and not give preference to others. This approach is implemented after discussing the results of studies by research and teaching staff.

The survey allows to determine the general views, opinions of people in certain areas, identify the motivation of their activities, the system of relations. There are the following options for the survey: personal (with direct contact between the researcher and the respondent) or indirect (questionnaires are distributed by distribution, and respondents respond to them at a convenient time); individual or group; continuous or selective. A special questionnaire is used for the survey. Based on the fact that the questionnaire is a research document developed according to the established rules, contains a number of questions and statements organized by content and form often with answer options, its development requires special attention and thoughtfulness. The questionnaire should consist of the following parts:

introductory, which contains the survey purpose, motivation for it, the importance of the respondent's participation, the guarantee of privacy, and clear rules for filling out the questionnaire;

the main part, consisting of a list of questions to be answered;

socio-demographic, designed to identify basic biographical information and social status of the respondent [7].

\section{RESULTS AND DISCUSSION}

To form the recommendations on the organizing educational process of training applicants for the higher education the first (bachelor) level of specialty 026 Performing arts (field of knowledge 02 Culture and art), we have formed a questionnaire [8]. The survey was anonymous. It involved 80 applicants from five higher education institutions (Fig. 1).

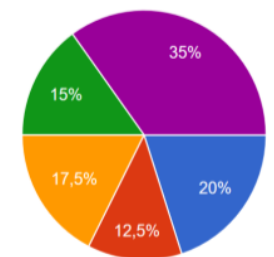

Figure 1. The ratio of participation in the survey of applicants for higher education:

- Kyiv National University of Culture and Arts; Communal institution of higher education Uzhhorod

- Institute of Culture and Arts of the Transcarpathian Regional Council;

- Lugansk State Academy of Culture and Arts;

- Ternopil Volodymyr Hnatiuk National Pedagogical University;

- Kharkiv State Academy of Culture

The distribution of answers to the question "What are your expectations after graduating from the educational program of your choice?" is shown in Fig. 2.
Most of the respondents (35\%) are planning to work in the event industry and others in the theater or on television. The essence of their answers was manifested in the combination of the proposed activities.

The term "event" means a professionally planned and organized event in the cultural, leisure and marketing spheres. It can be arranged for a certain group of people who perceive it as something significant and unique. Its realization is limited by time and space, provided by the use of various resources, and aimed at solving specific tasks and reaching particular goals. Therefore, the director needs modern managerial thinking and special knowledge of technologies used during events, learning the theoretical and practical foundations of the event industry, mastering the skills of professional planning, organizing events in business, public and private life, including concept and program development, budget formation and control, coordination work of subcontractors, as well as studying the effectiveness of the organized holiday event [9].

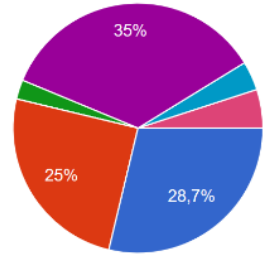

Figure 2. The distribution of answers to the question "What are your expectations after graduating from the educational program of your choice?"

planning to work in the theater;

- planning to work on television;

planning to work in a circus;

planning to work as an animation/entertainment program organizer;

planning to work in the event industry;

- considering the possibility of working in the institution of higher education that I graduate from;

another answer

Having received answers to the question "Do you have the opportunity to be a stakeholder in your institution of higher education (to influence changes in the organization of the educational process)?" was found that $73.8 \%$ of respondents believe that according to the results of their surveys there have been some changes, in particular, a small part of them $(7.5 \%$ of the total number) are representatives of student government and defend the interests of applicants. $26.2 \%$ of applicants do not have the opportunity to influence changes in higher education institutions and believe that the existing mechanisms for working with students as stakeholders just a formality.

There were grouped answers to the question "What competencies, in your opinion, should you developed to be ready to work in the specialty 026 Performing Arts?", and created the following list:

creativity, clarity of speech, directing theoretical and practical skills, ability to develop aesthetic taste; 
concentration, ability to manage the creative process, the ability to come up with creative and original ideas and implement them;

ability to understand the technical field of light and sound equipment;

ability to convey feelings and emotions;

ability to initiate innovative stage projects, festivals, and competitions, to promote the best examples of national and world stage heritage;

ability to comprehensively solve complex professional problems in the field of stage innovation with a deep rethinking of existing, and the creation of new holistic knowledge and professional practice;

ability to understand and comprehensively assess the fundamental principles of cultural and artistic processes;

ability to communicate with the general professional, scientific community and the public in the field of performing arts and production, to interact with representatives of other creative professions at the international level;

ability to correlate personal understanding of an artistic idea and work with the external context;

ability to generate and develop a new creative idea and embodiment it in a work of performing arts;

ability to complex use of a specific system of expressive methods (plastic-pictorial, sound, acting-performing, editing-compositional, script-dramaturgical) in an independent creation and production of a stage work;

ability to work effectively in the team during the process of creating a harmoniously holistic stage production, the ability to lead the work, and participate in the creative team in the preparation process;

ability to critically analyze, estimate and incorporate new complex ideas in creative and production stage activities; stress-resistance;

tolerance and sense of humor;

ability to work in a team and project management.

The distribution of answers to the question "Are you studying something extra outside the institution of higher education to feel more ready to work in the specialty 026 Performing Arts?" is shown in Fig. 3.

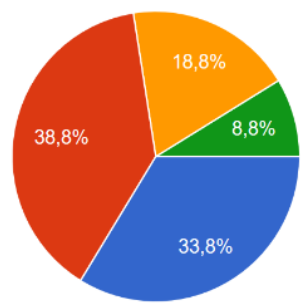

Figure 3. The distribution of answers to the question "Do you study something extra outside the institution of higher education to feel more ready to work in the specialty 026 Performing Arts?"

- yes, I attend various masterclasses by practitioners; yes, I take various online courses on different

- platforms;

- no, there is no such need;

- another answer
Such responses indicate that applicants for higher education are not indifferent to their future professional activities, but higher education institutions do not fully meet the needs of applicants. Additional information provided by applicants draws attention to the importance of combining training with practical activities. They also pay attention to learning foreign languages and studying in other educational programs to ensure their possibilities in the labor market.

The distribution of answers to the question "Do the educational process organizers involve practitioners specialists in the specialty 026 Performing Arts?" is shown in Fig. 4.

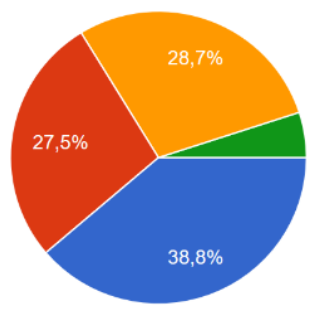

Figure 4. The distribution of answers to questions "Do the organizers of the educational process involve practitioners - specialists in the specialty 026 Performing Arts?"

- yes, we have many scientific and pedagogical employees who implement the educational program, successfully combining practical professional activity with scientific and pedagogical;

- yes, we sometimes have classes with influential figures in the field of performing arts;

- very rare, once in a while;

- another answer

The distribution of answers to the question "Are there any problematic issues in the logistics of your training?" is shown in Fig. 5.

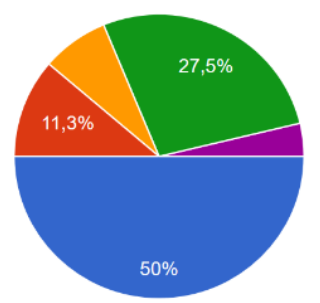

Figure 5. The distribution of answers to the question "Are there any problematic issues in the logistics of your training?"

- I am completely satisfied with the logistics;

- the logistics are available, but not all equipment is accessible;

- in fact, there are problems with certain equipment, it is not cheap, but it is planned to purchase it soon;

- the logistics need significant updating;

- another answer 
The applicants pointed out that they can't use specialized auditoriums due to the spread of COVID-19, and they need to study remotely.

The distribution of answers to the question "Do you have opportunities for internships in higher education institutions of other countries that prepare specialists in the same specialty?" is shown in Fig. 6

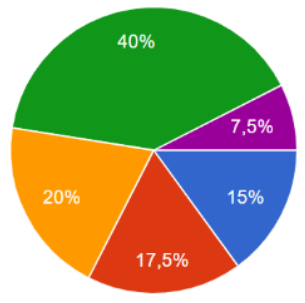

Figure 6. The distribution of answers to the question "Do you have opportunities for internships in higher education institutions of other countries that prepare specialists in the same specialty?"

- yes, but this opportunity can be used by the best applicants;

- yes, but it's not cheap and can be afforded only by well-off applicants;

there is no such possibility;

- I was not interested in that;

- another answer

The applicants pointed out that such a possibility exists. The Free Economic Zone has agreements on such cooperation. Everyone knows about it, however, in their opinion, it has no use. Only $3-5 \%$ of full-time education students can afford an internship in another country but there is no such opportunity for part-time higher education students. Everyone has more opportunities for internships abroad through employment in the specialty. But the existing quarantine conditions do not allow to take advantage of this.

The distribution of answers to the question "Does your higher education institution have the practice of forming projects by higher education applicants and presenting them to employers' representatives?" is shown in Fig. 7.

Two-thirds of higher education students answered positively to the question "In your opinion, is it necessary to carry out training in your program in a dual form of education (combining training and professional activities)? If so, justify your opinion", explaining it by the lack of practice and lack of feeling readiness for work in the specialty.

The distribution of answers to the question "Do you think there is enough practical training in your preparation?" is shown in Fig. 8.

The distribution of answers to the question "How does the environment of a higher education institution affect your motivation to study in an educational program?" is shown in Fig. 9.

Substantiating their opinion, students mainly pay attention to teachers, and their opinions are divided into positive and negative (this applies to all higher education institutions). In particular, the positive ones include good directing works of teachers, most of the teachers are talented and true professionals. To the negative - lack of mutual understanding, unwillingness to develop, and help students. The faculties do not interact with each other and there is constant negative competition between them. There is no creative family as it should be. In addition, they point to the lack of conditions for implementing student plans and the lack of proper equipment, as result students always spend their own money for its rent. Distance learning also reduces motivation.

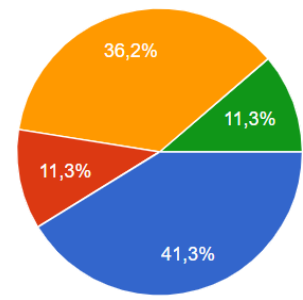

Figure 7. The distribution of answers to the question "Does your higher education institution have the practice of forming projects by higher education applicants and presenting them to employers' representatives?"

yes, we have such events all the time. I have also taken part in them;

there are such opportunities, but in my opinion, they

are not effective;

the institution of higher education does not hold such events but keeps students informed about similar events held by other organizations where they can participate;

another answer

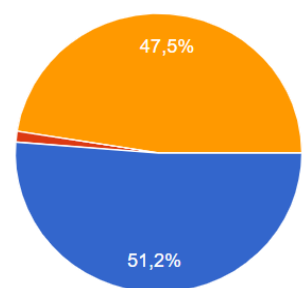

Figure 8. The distribution of answers to the question "Do you think there is enough practical training in your preparation?"

- the educational program I am studying is well balanced with different types of classes;

- the number of practical classes needs to be reduced;

- the number of practical classes needs to be increased;

- another answer

The distribution of answers to the question "Do you have the opportunity to determine the topic and content of your creative project or research?" is shown in Fig. 10

The distribution of answers to the question "Is the information that should be provided by a higher education institution accessible, clear and timely?" is shown in Fig. 11.

Two reasonings in the answer clarifications fully characterize all higher education institutions - negligence, 
delivery of not always clear information (sometimes teachers give the same information over and over again in different ways, which is very confusing).

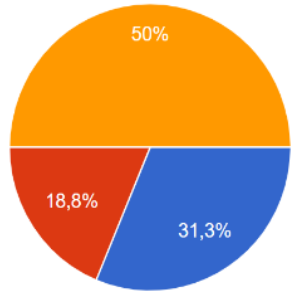

Figure 9. The distribution of answers to the question "How does the environment of a higher education institution affect your motivation to study in an educational program?"

does not affect;

- negatively, reduces it;

positively, increases it

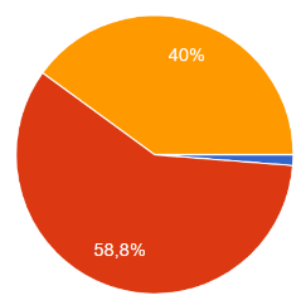

Figure 10. The distribution of answers to the question "Do you have the opportunity to determine the topic and content of your creative project or research?"

- no;

- yes;

- depends on if it goes or not beyond the educational/academic discipline;

- another answer

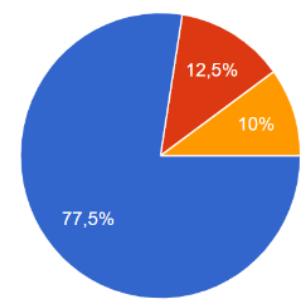

Figure 11. The distribution of answers to the question "Is the information that should be provided by a higher education institution accessible, clear, and timely?"

- yes;

no;

another answer

We have concluded by studying the answers to previous questions by students from the same higher education institution.

Answers to the question "What problems do you meet during the learning process and how these problems are solved?" were received:

lack of proper information for students about the educational program implementation, its individual educational components, and additional opportunities to achieve program learning results;

insufficient training in the specialty;

lack of ability to achieve program learning results due to quarantine and remote learning process, which leads to the lack of any practice;

lack of stable internet;

lack of independent choice of individual tasks (the choice is made only by teachers);

lack of proper individual work assessment, substantiation of complete information (does not apply to all teachers); lack of support from teachers in the deficiency of creative ideas from students (does not apply to all teachers);

lack of necessary elements and technical equipment (students rent or buy with their own money).

The distribution of answers to the question "Are your academic achievements and those of your colleagues always evaluated fairly?" is shown in Fig. 12.

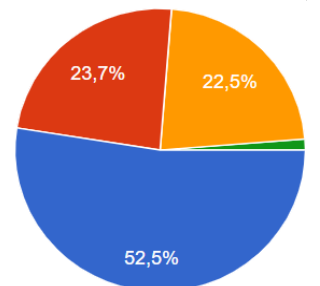

Figure 12. The distribution of answers to the question "Are your academic achievements and those of your colleagues always evaluated fairly?"

yes;

- no;

- I don't care about it, even if there are cases of unfair assessment -

I do not pay attention to it;

- another answer

The distribution of answers to the question "Are you satisfied with the use of distance education technologies and assistance to the students during its use?" shown in Fig. 13.

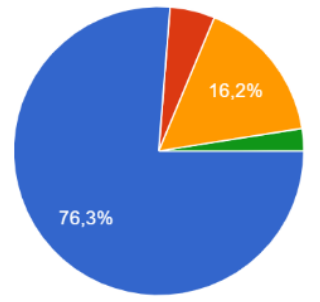

Figure 13. The distribution of answers to the question "Are you satisfied with the use of distance education technologies and assistance to the students during its use?"

- yes;

- assistance to the students during the use of distance education technologies is not provided;

no;

another answer

Applicants also pay attention to the low level of teachers' qualifications in the use of distance education 
technologies and the fact that practical classes in distance education are not perceived at all.

The following main answers to the question "What are your suggestions for improving the organization of the educational process in your higher education institution in general, and in particular in the specialty, that are aimed at increasing your competence for work in the field of performing arts?" were received from students from all higher education institutions:

in the content of educational programs:

-increase the amount of time for professionally-oriented disciplines (in particular, increase the time for studying Stage Speech, more detailed study of video editing and work with music and light),

- increase the number of practical classes;

minimize distance education;

provide students with equal rights and opportunities;

to create a feedback system with students in a higher educational institution;

update the employment scheme for the educational system; constantly upgrade the skills of research and teaching staff by specialty and on distance education technologies;

to provide masterclasses held by well-known professionals and practitioners in the specialty 026 Performing Arts;

to update the logistics of the educational process, create specialized classrooms and stages;

to form information support of the educational process (to inform students about internships, international opportunities, grant programs directly on the website or throw social networks).

\section{CONCLUSION}

The material reveals the problem of the lack of higher education standards in Ukraine of the first (bachelor) level of specialty 026 Performing arts (field of knowledge 02 Culture and art). According to the survey results of the stakeholders' (applicants for higher education), the elements of the project of such a standard and ways of development of higher education institutions that prepare specialists in the specialty 026 Performing Arts are proposed:

1. The training of applicants should be carried out only in a dual form of education, which involves on-the-job training in enterprises, institutions, and organizations to acquire a certain qualification in the amount of 25 to 60 percent of the total volume of the educational program based on the contract. On-the-job training also involves the performance of official duties following the employment contract. The dual form of education is carried out based on an agreement between the institution of higher education and the employer (enterprise, institution, organization, etc.), that provides coordination of the job of a higher education applicant and payment for his work;

coordination of the learning amount of the applicant in the workplace and the expected results;

coordination of obligations of the higher education institution and the employer of implementation of the individual curriculum by the applicant in the workplace; coordination of the procedure for evaluating learning outcomes obtained in the workplace [4].

2. The proposals formed by applicants are new pedagogical conditions that need to be organized and implemented in the educational process:

to create an information support system of the educational process and feedback with applicants;

to create a system of professional development of teaching and research-pedagogical staff of higher education institutions.

During the development of these systems should study the research of famous scientists in this field N. Gusakova [6], R. Nabokov [9], M. Medvid, V. Dem'yanyshyn, I. Shernichenko, V. Honchar, V. Liutyi [10], and others.

Further research will be devoted to the implantation of certain conditions in the educational process based on the results of a survey of applicants and a pedagogical experiment to assess their effectiveness.

\section{REFERENCES}

[1] On approval of the list of branches of knowledge and specialties in which the training of higher education seekers is carried out: Resolution of the Cabinet of Ministers of Ukraine of April 29, 2015, № 266 [URL: https://zakon.rada.gov.ua/laws/show/266-2015$\% \mathrm{D} 0 \% \mathrm{BF} \# \mathrm{Text}$, [in Ukrainian]

[2] Draft standards of higher education of Ukraine: official website of the Ministry of Education and Science of Ukraine [URL:

https://mon.gov.ua/ua/osvita/visha-osvita/naukovometodichna-rada-ministerstva-osviti-i-naukiukrayini/proekti-standartiv-vishoyi-osviti], [in Ukrainian]

[3] Approved standards of higher education in Ukraine: the official website of the Ministry of Education and Science of Ukraine [URL:

https://mon.gov.ua/ua/osvita/visha-osvita/naukovometodichna-rada-ministerstva-osviti-i-naukiukrayini/zatverdzheni-standarti-vishoyi-osviti], [in Ukrainian]

[4] On higher education: Law of Ukraine of 01.07.2014 № 1556-VII [URL:

https://zakon.rada.gov.ua/laws/show/266-2015$\% \mathrm{D} 0 \% \mathrm{BF} \# \mathrm{Text}$, [ in Ukrainian]

[5] M. Medvid, O. Komisarov, O. Merdova (2018), Review of the tasks of formation and progress of human resources in the sustainable development strategy of ukraine in the light of central place theory, Baltic Journal of Economic Studies, 4, 2, pp. 134-140. DOI: https://doi.org/10.30525/2256-0742/2018-4-2-134-140 
[6] N. Gusakova (1999), Pedagogical conditions of formation of creative personality of the director of amateur theatrical association: author's ref. dis ... cand. ped. Science: 13.00.06; Kiev. nat. University of Culture and Art. 19 p., [In Ukrainian]

[7] V. Zhigir (2010), Methods of research of statistical data of professional pedagogy in preparation of managers for educational activity, Youth and the market, 7-8, 60-65.

[8] Questionnaire for applicants for the higher education of the first (bachelor) level in the specialty 026

Performing Arts (field of knowledge 02 Culture and Art) [URL:

https://docs.google.com/forms/d/1d1g1qSU6dhtvkFLJ4TqjYvAor8zTK6PT3Iv3p4iNQE/edit] [in Ukrainian]
[9] R. Nabokov (2020), Specific Features of Directing and Art Technologies in Creating an Event Product, Culture of Ukraine, 70, pp. 201-210, [in Ukrainian]

[10] M. Medvid, V. Dem'yanyshyn, I. Chernichenko, V. Honchar, V. Liutyi (2021), The Development of Readiness for the Educational Activities in Teachers of Higher Military Educational Institutions, Proceedings of the 2020 3rd International Seminar on Education Research and Social Science (ISERSS 2020), Advances in Social Science, Education and Humanities Research, volume 516, pp. 416-422. DOI:

https://doi.org/10.2991/assehr.k.210120.077 